\title{
5 \\ The ABCs of Fractal Thinking in Higher Education
}

\author{
Edward Nuhfer \\ Idaho State University
}

All learning establishes and often stabilizes neural networks in the brain. These carry both cognitive and affective attributes and have fractal form. Fractal networks produce many actions and products that exhibit fractal qualities. Awareness of such qualities provides a unifying key to understanding and applying educational knowledge. It represents a marked shift in perception that differs from thinking customarily employed in considering information as a specialist. This alternate perspective helps professionals in higher education draw on diverse information from specialty research and apply it more effectively.

$F_{\text {abilities to visualize fractal traits within teaching, learning, thinking, per- }}^{\text {ractal thinking, a term coined simply for brevity, describes individuals' }}$ formance, and in assessment and management of these. My exposure to fractal thinking developed through sheer luck: a background as a natural scientist and college teacher, and a fortuitous opportunity in 1988-1989 that introduced me to fractals during the same sabbatical that introduced me to faculty development. It took a decade as a practicing developer before my own brain connected the two (literally, not figuratively, as we shall soon see). Only then did I realize how much fractal thinking had to offer to my practice and to higher education in general. Since becoming conscious of the connection, I enjoy a new fascinating insight at least monthly, which makes me passionate about sharing fractal thinking with others.

This chapter begins by providing awareness of the nature of fractal forms-the ABCs. It follows with a summary of the sparse information now relating fractals to higher education and explains why fractals should be use- 
ful. It next provides examples of application to some of the toughest problems in higher education.

The model presented is conceptual and stresses pattern recognition and visualization rather than numerical analyses. As such, it does not require mathematical training to understand and apply it. If you address the complex problems of student learning, teaching evaluations, grading, assessment of student learning, curricular development, or faculty development, you will find something of value. Fractal thinking will help you to choose efforts that will promote tackling such issues successfully and help you to foresee some reasons why particular approaches are likely destined to fail.

\section{First, What's a Fractal?}

Nature is full of fractal geometric forms that are familiar to all readers: trees, clouds, landforms such as meandering streams or continental coastlines, and biological systems such as blood vessels of the vascular system or neural networks of the brain (Liebovitch, 1998; Mandelbrot, 1982). To those in "the pre-fractal awareness stage," such forms appear impossible to quantify or to describe other than in terms such as random, irregular, or perhaps confusing. Fractal thinking brings awareness that intimidating complexity often stems from a simple source that provides a means to understand a complex challenge in surprising and deep ways. It's easiest to learn the nature of fractals by seeing a picture of a fractal form's development (see Figure 5.1).

FIGURE 5.1

Development of a Fractal Form

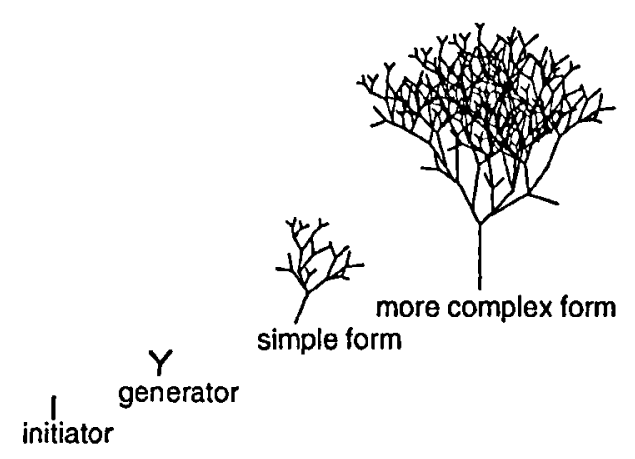

Note. From Nuhfer (2003b). The fractal form of an increasingly complex branching network is built from recursive operations on a generator in which each branch of the " $\mathrm{Y}$ " is replaced repeatedly with subsequent " $Y$ " shapes. 
Note first the single line labeled as the initiator in Figure 5.1. Simple manipulations of a line cannot produce a fractal. We can extend it, bend it, close it upon itself, and produce an infinite number of shapes, some of which are the Euclidean forms so familiar to us from K-12 mathematics (rectangles, trapezoids, circles, sine waves, etc.) without producing a fractal form. The generator is the required building block for a fractal form. The generator parts are Euclidean; in this case a " $Y$ " has three parts, all straight lines. Building a fractal form requires using the generator in a recursive process that involves a repetitive action, in this case replacing each arm of the " $Y$ " with yet another "Y." Leafless trees clearly exhibit fractal forms similar to forms shown in Figure 5.1. The figure reveals two important fractal traits: 1) fractal forms are made of parts similar to the whole in some way, and 2) fractal forms appear similar when viewed at different scales. Certainly, the branching nature is apparent as a similarity through all parts. Further, if we have no reference scale, it could be difficult to tell whether we are observing a seedling from a few feet away or an immense tree from a distance by looking at an object similar to that depicted in the more complex form of Figure 5.1.

The pattern in Figure 5.1 is imminently applicable to education because it provides a reasonable portrayal of change produced in the brain during learning. Leamnson (1999) was the first writer to broadly encourage college teachers to recognize learning as the building and stabilizing of synaptic connections and developing of neurological networks. Given a normal, healthy human brain, efforts to learn will produce branching neural networks that give us increased skills and developed thinking abilities. Prolonged effort and practice eventually provide abilities that separate expert from novice and an uneducated person from an intellectual. Teaching, like any skill, produces a complex neural network through prolonged study and practice. In fact, complex networks need to be developed before high-order thinking tasks can be successfully handled (Iannaccone \& Khokha, 1996). We might consider the simple form in Figure 5.1 as representing the neural network of our students and the more complex form representing that of a professor. However, even the more complex network of Figure 5.1 is an oversimplification. Real neural networks possess much greater density, grow in three dimensions, and the branched interconnected forms themselves are interfolded (Iannaccone \& Khokha, 1996). Learning produces fractal networks that are astounding in complexity and incredible in functionality. Further, the network is merely circuitry. When the circuits are active-when an electrical impulse involved in a thought in a single area triggers impulses in other areas with different sequences and in varied intensities-the electrical 
cascades represent a chaotic pattern with astounding possibilities. When viewed in this way, it is easy to see why the human brain is truly capable of infinite thinking with countless variations.

We now close in on part $\mathrm{C}$ of the $\mathrm{ABCs}$ of fractal thinking. The two qualities we have considered-fractal forms made of parts similar to the whole (A) and fractal forms appearing similar when viewed at different scales (B)are still insufficient to define a fractal. Some Euclidean forms also meet these criteria. Consider a cube made of 1 -inch cubic building blocks 10 blocks wide, 10 blocks high, and 10 blocks deep. Although the cube is made of parts similar to the whole, and the form appears similar when viewed at different scales, it is a Euclidean form. It lacks a fractal's signature trait: (C) a fractal form's dimensions change depending on the instrument used in the measure. In the cube example, no matter what size ruler we use to measure it, an edge will remain 10 inches long, the area of a face will remain a constant 100 square inches, and the volume will remain 1,000 cubic inches. This results because Euclidean forms are smooth and their dimensions have fixed quantities of length, width, and height. In contrast, fractal forms are rough rather than smooth, and their dimensions change in accord with the resolution of the instrument that measures them.

Consider what happens when we try to measure a fractal form, such as the length ( $\mathrm{L}$ ) of a seacoast between two points. A land-sea interface is just a line-an irregular continuous line that is perhaps as simple as any fractal form can be. If we have a map of the seacoast (see Figure 5.2), we can use a divider as a measuring tool. We can set the divider at a known width ( $r$ ) and march the divider along the coastline from starting point to end point. We sum the number of divider steps $(\mathrm{N})$ between the two points, multiply this sum by $r$, to arrive at a length ( $L$ ) of the coastline. However, if we set the divider at a markedly shorter width, repeat the measure, and total that number of divider widths, the process reveals a markedly longer coastline than the former length we derived. If we go to larger maps that show more resolution, the coastline grows with every effort to measure it in increasing detail. A very small divider width (e.g., $r$ equal about the size of a sand grain) applied along an actual coastline (rather than a scaled map) would capture such detail that the result would be essentially an infinitely long coastline. Unlike the cube edge, there is no "right answer" of seacoast length as a unique number. The harder we try to measure it, the bigger it gets.

Although many may intuit that a very crooked line (like a coastline) measured at first crudely and then more precisely might display an increase in length, intuition alone would not suspect the strength of the relationship between $r$ and $L$. The points generated by each $(r, L)$ pair generated from 
FIGURE 5.2

\section{Measuring a Fractal Form}
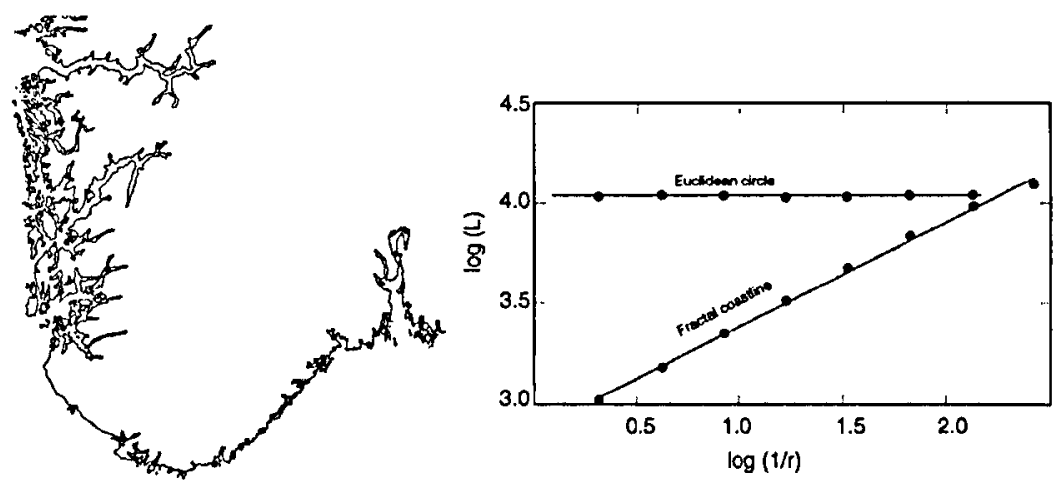

Note. Modified from examples in Feder (1988). Left, a map of part of a coastline in Norway. Right, the graph of change in coastline length $(\mathrm{L})$ that results from multiple measures of the coastline by dividers set at different widths ( $r$ ). The length of the coastline increases in a highly ordered manner as the feature is measured multiple times with dividers set at shorter spaces for increasingly greater resolution. This results in a plot of $\log (1 / r)$ versus $\log (L)$ that describes a line with a steep slope (graph, lower). In contrast, Euclidean forms like circumferences of circles have a constant length $(\mathrm{L})$ that changes little when measured with dividers set at varying widths of $r$. The slope of that plot of $\log (1 / \mathrm{r})$ versus $\log (\mathrm{L})$ describes a line of markedly less slope (graph, upper).

multiple measures taken at different divider widths, if graphed through appropriate scaling, will plot neatly along the same straight line (as in Figure 5.2). The pairs are often plotted with an ordinate, $\log (\mathrm{L})$, and abscissa $\log$ $(1 / r)$. While a fractal form does not have a simple length, it has a characteristic quality termed the fractal dimension, which can be expressed by a single number associated with the slope of line: $\log (\mathrm{L}) / \log (1 / \mathrm{r})$. Multiple measures taken along a true fractal form produce $(r, L)$ pairs that plot on a best-fit line with a pronounced slope. Multiple measures made on Euclidean forms (e.g., the length of the circumference of a circle) will reveal very little change in length with measures taken at different divider settings. The resultant line fit through $(r, L)$ pairs shows little slope.

Fractals not only describe geometric forms of physical objects, they also describe particular patterns in time (Nuhfer, 2005d). Rainfalls, floods, earthquakes, tsunamis, sediment accumulations, and volcanoes act mostly through fractal patterns in time. These patterns also possess the same $A B C$ qualities. By becoming aware of these three concepts-the $\mathrm{ABCs}$ of fractal thinkingany educator can begin gaining insights of value to higher education. 


\section{Previous Work}

Because the brain employs fractal neural networks (Iannaccone \& Khokha, 1996), it is likely that most human knowledge and activity exhibit some fractal qualities. In 1987, a bestselling book took the mathematics specialties of chaos theory and fractal geometry and introduced their relevance to laypersons (Gleick, 1987). More reference books quickly followed, as others saw applicability of fractal thinking to business, science, and social science, but little awareness has yet spread to education. A few workers made brief mention of fractals in association with higher education and drew general connections between their practice and fractal properties. Duffy and Jones (1995) use "fractal" to describe their perception that their "Rhythms of the Semester" ( $p$. xvi) could be seen at scales other than the semester, but they may have applied "fractal" to a non-fractal pattern (Nuhfer, 2005d). Wright (2001), summarizing institutional accreditation, writes, "All of this reminds me of fractals, which I first encountered about five years ago in a book by Margaret J. Wheatley called Leadership and the New Science" (p. 50). Cutright (2006) also cites Wheatley's work when examining applicability of chaos theory to the administrative realm of planning in higher education.

We introduced our fractal model for higher education in 2002 at the PacPair Conference in Hawaii (Nuhfer, Chambers, \& Heckler, 2002). Two well-received pre-conference workshops at the 2002 and 2003 American Association for Higher Education (AAHE) assessment conferences followed (Nuhfer \& Pletsch, 2002,2003 ), which generated awareness in a number of assessment directors. Because assessment was both a relatively new and rapidly developing profession within higher education, the AAHE assessment conferences brought together educators from diverse institutions who were unusually receptive to new visions and who sought interconnections. The losses of the AAHE assessment conference and of AAHE itself were setbacks for higher education, and nothing comparable has yet replaced either. The Lilly Conference in Oxford, Ohio, hosted fractal workshops in 2004 and 2005. Several disciplinary organizations, colleges, and universities hosted invited workshops as result of the introductions at conferences. The Boot Camp for Profs ${ }^{\circledR}$ program evolved into a systematic, integrated development program based on fractal thinking. Since 2003, the National Teaching and Learning Fortum has featured more than 15 articles on application of fractal thinking to faculty development and higher education.

\section{The Value of Unifying Concepts}

The value of unifying concepts is less about unique discoveries than about their effects in making dispersed information more relevant and accessible. 
For example, the unifying concept of plate tectonics in geology did not accompany a specific discovery involving rocks, ore deposits, field geology, geochemistry, geophysics, oceanography, seismology, vulcanology, stratigraphy, and so on. Each of these specialties contributed knowledge and made impressive discoveries without any unifying theory. However, once plate tectonics made obvious the connections among these specialties, it greatly expedited understanding. In a short time, freshman students understood more about how the Earth worked from one course than their predecessor professors understood with a graduate degree. This, in turn, produced scientists equipped with more powerful models for deeper understanding, and certainly permitted newer discoveries in all these specialty areas at a faster rate than was previously possible. The concept had a profound effect from the level of individual scholar to an entire disciplinary profession. This effect across scales is a fractal trait and exemplary of the power enacted by a new concept.

In higher education, rich knowledge acquired in development of particular pedagogies, learning styles, levels of thinking, evaluation, assessment, course design, curriculum design, specialty education in disciplines, education designed for humans in different developmental stages, use of technology, and the like remains possible without any unifying theory, but these specialties remain largely unconnected. As a result, faculty who seek to develop better practice are similar to new geology students of the 1950s. Development of competence and professional philosophy requires long study and practice in consulting disparate specialty literature. Even when this literature is drawn together in various teaching improvement books, the narrative discloses little connectivity between content presented in separate chapters.

In higher education, a recent unifying concept relates teaching, learning, and thinking to brain function. Leamnson (1999) tied research on adult learning to brain neurology in a well-integrated, usable resource for the general college teacher. Zull (2002) followed with a book of similar focus that stressed brain neurology and portrayed particular learning style activities arising from particular regions of the brain. Learning style preferences almost certainly result from preferential development of particular neural networks. Both these books consider maturation of the brain, which explains why child learners and college students think differently and require different teaching approaches. One holistic way to consider education is to examine the brain's neurological development in response to teaching, learning, and thinking. Fractal thinking extends this consideration to include the fractal qualities of the brain together with the fractal qualities found within the performance, products, and practices generated from the brain. 
Douglas Reimondo Robertson, assistant provost and director of the Professional and Organizational Development Center at Northern Kentucky University, achieved an early awareness about the applicability of fractals and chaos theory to higher education. He has been able to use fractal thinking to good advantage in his work in faculty, instructional, curricular, and organizational development. He writes,

The fact that "fractal thinking" provides insights that have already been discerned, such as the necessity of multiple measures ... is not what it contributes in my mind. I think that its value is that it is a part of a whole perspective (paradigm, worldview, frame of reference, assumptive world, way of constructing reality ... pick your phrase), which, once integrated, provides insight after insight, effective practice after effective practice. It is not a single concept. It is an integrated whole conception of reality. There is an economy to embracing it. Rather than lugging around a bunch of loosely integrated insights ... one simply looks through this one lens and effective insights and practices come to one in one novel situation after another. For example, once I understand fractals and attractors, then I understand that when I walk into class on the first day, not only do I have the opportunity to create and support new and desirable patterns and forces, but I know that other patterns and forces already exist that will support or compete with my desired patterns and forces for the outcome of each moment of my course... (personal communication, February 23, 2006)

\section{Discussion and Sample Applications}

-Faculty Evaluation

The topic of faculty evaluation, particularly through use of student cvaluations, creates a huge volume of literature. By 1988, more than 1,300 articles existed (Cashin, 1988), and more than double that number exists today. How is it possible, after so many studies, that the topic still generates impassioned arguments and counterarguments instead of widespread acceptance and skillful application of the findings? Sometimes we yet even hear or read "Good teaching is so complex that you can't really evaluate it."

If this statement were true, we could not evaluate any other learned proficiency. Attempts to evaluate proficiency are, without exception, efforts to characterize specific parts of an individual's neural network. Proficiency in any discipline-accounting, chemistry, engineering, philosophy, theatre, or 
college teaching —each requires the individual to build an expert's neural network through study and practice. These networks are fractal, and proficiency is the expression of such a network in action. Because we cannot observe the networks directly, the only way to evaluate proficiency is through measuring well-chosen products and actions of such networks.

Fractal thinking even helps in considering what constitutes "multiple measures." Some consider "multiple" as different means of measurement, as in paper and pencil self-report and direct observation rather than the number of items within a single instrument. However, 10 different questions about a single topic given on a paper and pencil instrument really tap 10 different areas of the brain, much as different divider widths sample unique parts of a coastline. Thus, responses to different items truly qualify as multiple measures of a neural network, and this chapter considers multiple measures in that sense.

A lesson taken from the coastline example reveals that single measures cannot characterize even the simplest fractal form. Experts in evaluation invariably recommend that evaluators use multiple measures (Arreola, 2000; Theall, Abrami, \& Mets, 2001). However, practitioners often ignore expertise, and nowhere is the gap between expertise and practice larger than in the use of student ratings to evaluate faculty. Robert Leamnson describes the prevalent application.

Over 25 years I was evaluated by more than 100 groups of students. For about 18 of those years, I participated in annual reviews of my departmental colleagues and in those of all Arts and Science departments at the college level. The methods were virtually invariable. Whenever a rating form had a global question, it alone was considered and all else simply ignored! If, in the real world, you put a global question on the rating form ... the global question is the end-all and be-all-the alpha and the omega. (personal communication, November, 27, 2005)

Fractal thinking provides a stronger argument against this practice than even a reasoned appeal to authoritative recommendation based on dominant, well-established statistical trends. It addresses the concrete impossibility of using single measures to characterize fractal forms. Just as there will never be a "magic divider" to divine the true length of the coastline, there will never be a "magic item" and likely not even a single "magic form" that will allow us to divine the neural network of a teacher.

Could this perhaps support a pessimist's argument of teaching being too complex to describc? The answer is no. We recall (a bit of fractal thinking now!) that multiple measures allowed us to derive the fractal dimension of a 
coastline. The fact that we could not measure a unique length did not preclude our characterizing it in such a way that we could begin to understand it and to compare it with other coastlines. With a bit of additional fractal thinking, we will realize that established precedents exist in which selected multiple measures prove capable of characterizing specific neural networks. Perhaps the best-known precedent is the Myers-Briggs Type Indicator ${ }^{\circledR}$. This tool takes between 93 and 125 measures in order to characterize dominant personality types. It has proven itself over many years to be reliable and valid. Another demonstrable success involving multiple measures is the Kolb Learning Style Inventory (Smith \& Kolb, 1986). Both diagnostic tools use multiple items carefully selected to trigger responses from different networks of the brain involved in choices, and the results provide good characterization of the neural network being investigated. Although Myers, Briggs, and Kolb recognized that they needed a minimum number of measures, they lacked the unifying concept to explain why they could not diagnose types with only a few items.

How many measures do we need? A perceptive reader might note, "Look, we could characterize the fractal coastline in Figure 5.2 with just three good measurements needed to establish a line fit-why not three for a neural network?" The answer is that we are not characterizing a neural network that is remotely so simple as a coastline. The second is that networks we must characterize for faculty evaluation are not one system, but several that are interconnected. This is akin to the network involved in personality type coexisting and interconnected with those of learning style and intelligence type. The third is that established precedents for diagnosing such types seem to require several score of measures for each. The neural network that a professor develops is much larger and more complex than the networks characterized by these inventory types. In fact, it includes them. For the same reason we cannot derive personality or learning style types by single questions, we cannot know or evaluate instructional proficiency by the prevalent, yet hapless, practice of using a single global response item. My estimate is that we need close to 200 measures from students to be confident that we understand an instructor's teaching effectiveness from just the students' point of view. This would include about 150 or more items from a knowledge survey, about 40 to 60 formative items, and 3 to 5 summative global items (Nuhfer, 2005b).

\section{Understanding the Controversy}

Failure to appreciate the capacity of complex neural networks leads to a kind of Euclidean thinking that envisions topical knowledge as akin to the set volume of a cube is probably one of the worst side effects of establishing 
expertise. It erupts whenever a person accepts that current knowledge and prevailing interpretations constitute all worth knowing about a topic. The massive literature of student evaluations contributed to such a view. For many years, the research on student evaluations focused on teaching traits with an expected link to cognitive learning. Feldman (1986) is a significant exception. When reports such as Ambady and Rosenthal's (1993) "thin slice" studies determined that students' ratings for teachers after watching 30 seconds of silent content-free video were highly consistent $(r=0.76)$ with end-of-semester ratings, some scholars reacted by attacking the importance and credibility of the findings. When scholarship on the relationship between physical appearance and success in the workplace extended into study of the relationship between physical appearance and its influence on student ratings (Hamermesh \& Parker, 2005), some scholars were livid. They openly speculated that the researchers themselves were physically unattractive, had records of low student evaluations (or both), or had some personal motivation to publish such research in order to deprecate student evaluations. Paradoxically, affective networks of experts produced a hostile reaction against the confirmation of the strength of affective relationships!

Fractal thinking anticipates the physical attractiveness and the thin slice results because both address first-impression phenomena. First impressions establish generators in the minds of students. Generators have overwhelming power in determining the final form, and the character of such generators should influence the nature of the neural network produced as a result of taking a course. Far from deprecating student evaluations, the studies confirmed the power of affective first impressions and revealed the astonishing speed with which such generators form. If improved student satisfaction follows from enacting the first class well dressed and operating in accord with one's highest aspirations and teaching philosophy, this is critically valuable information. A fractal thinker understands why such a first impression should have such a powerful effect.

Fractal thinkers also perceive why the vehement criticism should occur. The solid documentation of student ratings' relationship to cognitive factors led to countering individuals' reports of other influences as anecdotal myths and misbeliefs (Boice, 1990). This generated the expected aggrieved reactions (Fish, 2005; Trout, 1997) because networks built during establishment of professional identities and practiced philosophies carry affective components. Euclidean thinking senses that new findings threaten to displace old paradigms (i.e., "both interpretations cannot fit into the same cube"). However, fractal thinking senses that new findings do not displace old findings so much as they expand awareness (i.e., "there is more to this coastline than we 
thought"). From challenges like the coastline problem, fractal thinkers expect to find a number of significant correlations among student learning, student satisfaction, and many cognitive and affective factors. They expect that the more we look, the more we will find.

New unifying concepts are powerful as change agents in expert learners because they enable new generators to build by assimilating the vast existing resources of knowledge and skills. This produces major reorganizations that permit expanded ways of thinking. The effects we noted in the discipline of geology from plate tectonics and in the expanded awareness described by Robertson with regard to faculty, instructional, curricular, and organizational development are important case examples.

\section{: Evaluating Students and Assessment of Learning}

Let's first contrast evaluation with assessment. The common use of these terms as interchangeable synonyms differs in the ways higher education uses them, although there is just enough inconsistency in the latter to create confusion. In formal use, evaluation examines an individual's capabilities and progress. Tools such as tests and grades, projects, theses, self-evaluation, references, and work performance ratings are common tools for evaluation of individuals. Evaluation of individuals may also include affective traits such as enthusiasm, reliability, and integrity. Assessment focuses on units such as a class, a course, a departmental curriculum, or an institution rather than on an individual. In assessment, we work mostly with aggregate data. Aggregate affective traits, such as general morale, may be included. Some confusing exceptions occur in terms such as self-assessment, which has established precedent as applicable to individuals (Loacker, 2000) and a unit's self-assessment report, which is clearly a report based on aggregate reflection. Assessment of student learning outcomes focuses primarily on the aggregate work being done, instead of on evaluation of individual instructors who promote it or individual students who do it.

We often hear that we should teach in a variety of ways and come at the same material from many directions. Good teaching practices encourage students' use of many senses (visually, auditory, kinesthetic) or address several poles of Kolb Learning Styles (such as confronting one topic through reading, writing, drawing, and arguing). We less often hear about incorporating diversity into our evaluative methods. When evaluating students' learning, keep in mind that the neural network in question is fractal and more complex than most imagine. Thus, the more measures made and the greater the variety of approaches taken (within reason), the better. If students truly meet a learning 
goal, they can demonstrate learning through a variety of outcomes. A course that evaluates learning based only on multiple-choice tests likely is sampling too little of the neural network involved in the desired learning and perhaps too much of the network developed in short-answer test-taking skill. A mix of in-class short-answer and take-home reflective writing tests, projects, and assignments is better than a single kind of measure. Fractal thinkers tend to teach and assess with multiple means and to create parts of a course that have similarity consistent to the whole.

Many distinguished teachers believe their tests to be direct measures of students' knowledge. Such belief stems from picturing attempts to measure knowledge as akin to measuring a cube edge rather than a coastline. If the problem of measuring knowledge were as simple as measuring the dimensions of a cube, there would be no challenge at all to creating reliable tests. When we realize we are trying to measure a fractal neural network, we realize that even the best tests, including standardized tests such as the Force Concept Inventory of physics or the Geoscience Concept Inventory of the Earth sciences, are merely samples of the complex network. Creating a reliable test, confirmed by reliability estimates ( 0.0 expresses no reliability; 1.0 expresses perfect reliability) (Jacobs \& Chase, 1992), is challenging. A very good faculty-made test usually has a reliability of about 0.6 to 0.7 . Raoul Arreola, a well-respected psychometrician, estimates that the average faculty-made test has a reliability of about 0.2 to 0.3 (personal communication, April 14, 2005).

The literature of assessment talks about "direct" and" indirect" measures of student learning (Maki, 2004), but in reality all practical measures are indirect. The only true direct measure would require observing the extent of the neural network in the brain, which we see is beset by the same problem as measuring the length of a coastline. Even then, we would only be measuring the wiring. Understanding the function of the network would involve recording infinite possible sequences and combinations when the wiring is live and current flowing between synapses. Direct assessment of learning becomes an engagement in measuring the infinite, a task that is clearly impossible to accomplish. Instead, we have to deduce the neural network indirectly through examining what the particular neural network of the brain does.

The language of assessment provides two useful terms: goals and outcomes. A goal is a generally descriptive statement about desirable qualities that might typify proficiency. For example, one goal for proficient chemistry students should be to understand the nature of science and its methods. For proficient professors, one goal should be to understand the content of their disciplines and the frameworks of knowing within them. However, a goal in itself provides nothing measurable. We need the student and the professor to 
do something to demonstrate they can meet the goal. That "something" is an outcome, which yields some measurable product that demonstrates a skilled action. Here are five outcomes through which the chemistry student might demonstrate science literacy.

1) Consider a cookbook and an introductory textbook on nutrition. Distinguish which is technology and which is science, and justify your answer.

2) The can containing the soda on your desk is made of aluminum. The can has a really bad attitude! Which statement can be resolved through science and why?

3) Marie Curie discovered radium. Mark Twain wrote Tom Sawyer. If neither Curie nor Twain had been born, what would we likely know about radium and Huck Finn? What does this show about how the reasoning in science differs from that of another discipline, such as literature?

4) Turn to Figure $X$ on page number $Y$, and explain the methods of science required to produce that figure.

5) If you wanted to see whether a job applicant understood science, create a question or challenge through which you might deduce such understanding, and explain why it is a suitable challenge.

Any teacher's fractal neural network can create limitless measurable outcomes that are nevertheless narrowly restricted to one goal statement. Thus, practical assessment of a curriculum requires that the faculty focus on a limited number of goals and outcomes and then publish these as guides for students.

All regional accreditation groups have chosen assessment of student learning outcomes as the primary focus of accreditation review. By now, some readers have probably realized that evaluation and assessment of student learning are also attempts to characterize fractal neural networks and are not surprised to hear about the need for multiple measures from experts in assessment (Banta, Lund, Black, \& Oblander, 1996; Maki, 2004).

Knowledge surveys (Nuhfer \& Knipp, 2003) are a fractal thinker's assessment tool because they provide a large number of measures focused on learning outcomes. They are not tests, but address more content than tests can practically sample, and they furnish numerical data amenable to the same numerical analyses as tests. A knowledge survey with about 200 items can be completed in about 30 minutes. A knowledge survey is also a type of student evaluation, and the literature of student evaluations applies in the understanding of knowledge surveys. The tool thus furnishes information about a neural network that summative student evaluations and tests cannot capture. 
It is perhaps the most useful of assessment tools for "closing the assessment loop" through readily supplying the data that targets areas for improvements and for tracking the results of changes (Wirth, Perkins, \& Nuhfer, 2005).

\section{Holistic Faculty Development Versus Remediation}

The development I initially learned is analogous to emergency room treatment: faculty member injured by student evaluations $\rightarrow$ diagnose the problem $\rightarrow$ recommend treatment options for content clarity and improved pedagogical engagement $\rightarrow$ patch up the faculty member's damaged confidence and send back to the classroom $\rightarrow$ follow up. Such development is remedial and centers on content and pedagogical delivery. Through experience, I learned that content knowledge and proficiency in multiple pedagogies are less than a third of what a successful faculty member really needs to succeed. Although we developers should provide emergency room treatment when required, faculty who enjoy more holistic development are involved in the equivalent of preventive medicine. They are less likely to need emergency

\section{FIGURE 5.3}

A Fractal Generator for Faculty Development

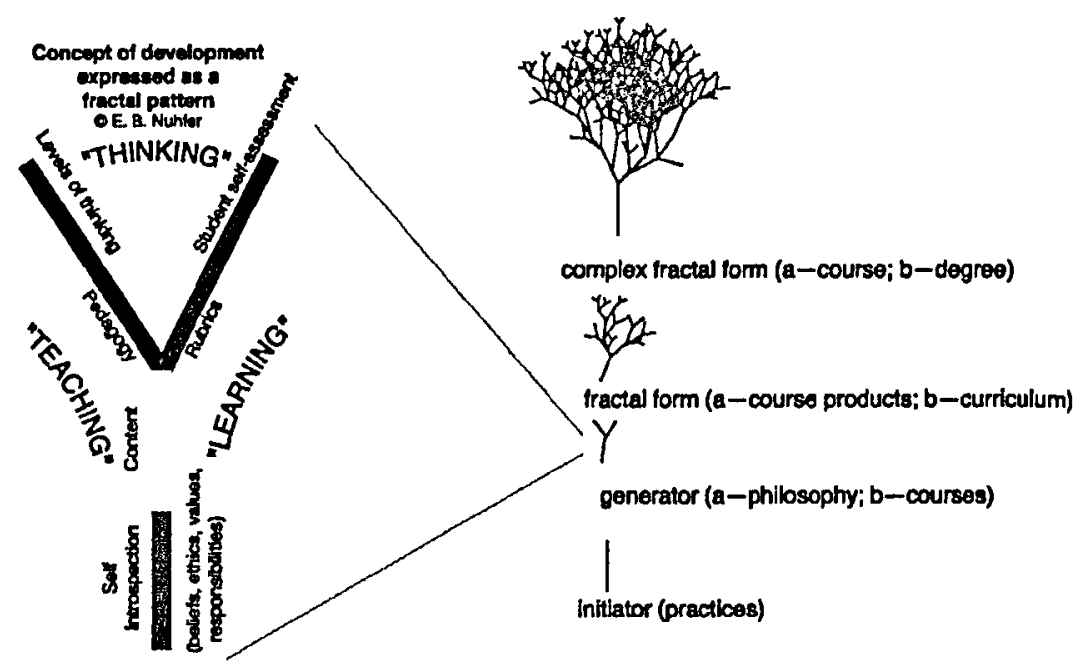

Note. From Nuhfer (2003b, 2003c). A fractal generator for faculty development showing six critical components needed for successful practice. The right side shows the place of the generator in forming an individual's products (a) and the same generator extended to a unit's (department, college/university) products (b). A strong teaching philosophy should reflect awareness of all six components of the generator. 
rooms. Fractal thinking provides a way to formulate a holistic development program. Successful teaching results from learning and experience that produces an effective neural network. Fractal thinkers ask, "What constitutes a good generator that can develop into such a network?" If we can provide that generator early in a faculty member's career, it should have positive formative power akin to that of first impressions. For years, I asked the question, "What development best serves faculty?" and I asked that question without fractal awareness. Finally, in 2001, I recognized that system I was beginning to design involved awareness of patterns across scales and that these had the same qualities as the fractal nature of rocks, landforms, and sediment layers I'd studied 12 years earlier. In retrospect, this particular "Aha!" moment had some admittedly "Well, duh ..." qualities because it took a dozen years before the particular synapses I'd developed doing science finally connected with those produced doing faculty development. The connection finally did boot the obvious into my awareness. Figure 5.3 encapsulates a generator suitable for holistic development that resulted.

An obvious product by which one might assess the state of a faculty member's development is a sophisticated philosophy (Nuhfer, Krest, \& Handelsman, 2003). A sophisticated teaching philosophy should reveal awareness of the full generator. The written philosophy is a critical document that is constantly growing and undergoing refinement as the neural network produced in our own continued learning grows more complex and more capable. Here the traits of a fractal form's parts being similar to the whole and the forms appearing similar when viewed at different scales become important. Our practices should stem from that philosophy, and so should our course products and the final learning outcomes of the courses. If fractal thinking is involved in construction of a course, the parts of the course should be similar to the generator. An individual who reads a syllabus or final examination should be able to discern important aspects of the writer's teaching philosophy. Likewise, each of us is part of something larger. We are in the business of providing education through curricula and degrees, and not in simply providing training through single courses. Thus, our philosophy must include awareness of our place within the larger effort, such that our efforts at the level of individual lesson, course design, and so on are always conscious of how our course contributes to the student's greater education as a major and a degree recipient from an institution (Nuhfer \& Adkison, 2003). The most important aspect, self-introspection, rests at the base of Figure 5.3. It is heavily affective in nature (Nuhfer, 2004a; 2005a), including what some would call the heart and soul of a teacher. We have elsewhere addressed the fractal nature of other components and products such as the following: 
- Content (Nuhfer, 2003a; Nuhfer, Leonard, \& Akersten, 2004)

- Evaluating content (Nuhfer, 2005c, 2005f)

- High-level thinking (Nuhfer \& Pavelich, 2001, 2002)

- Rubrics (Nuhfer, 2004b)

- The role of the affective domain (Nuhfer, 2004a, 2005a)

- Teaching philosophies (Nuhfer \& Adkison, 2003; Nuhfer, Krest, \& Handelsman, 2003)

- Temporal qualities of teaching, learning, and thinking (Nuhfer, 2005d, 2005e)

If you have made some connections now between fractals and your own awareness of higher education, you have made more progress in about 30 minutes than my brain made in more than a decade. Take this awareness into your practice. Start to think in scales and patterns as you look at efforts of individuals and units across your campus. Consider (A) whether these may be more successful if efforts at small scales are similar to the desired whole, and (B) seek to invest in those efforts that show similarity even though enacted at different scales. Finally, $(C)$ consider whether problems have solutions best met through Euclidean or fractal thinking. Pay attention especially to those that seem to grow the more people study them.

\section{References}

Ambady, N., \& Rosenthal, R. (1993, March). Half a minute: Predicting teacher evaluations from thin slices of nonverbal behavior and physical attractiveness. Journal of Personality and Social Psychology, 64(3), 431-441.

Arreola, R. A. (2000). Developing a comprehensive faculty evaluation system: A handbook for college faculty and administrators on designing and operating a comprehensive faculty evaluation system (2nd ed.). Bolton, MA: Anker.

Banta, T. W., Lund, J. P., Black, K. E., \& Oblander, F. W. (1996). Assessment in practice: Putting principles to work on college campuses. San Francisco, CA: Jossey-Bass.

Boice, R. (1990). Countering common misbeliefs about student evaluations of teaching. Teaching Excellence, 2(2).

Cashin, W. E. (1988). Student ratings of teaching: A summary of the research (Idea Paper No. 20). Manhattan, KS: Kansas State University, Center for Faculty Evalu- ation and Development. 
Cutright, M. (2006). A different way to approach the future: Using chaos theory to improve planning. In S. Chadwick-Blossey \& D. R. Robertson (Eds.), To improve the academy: Vol. 24. Resources for faculty, instructional, and organizational development (pp. 44-61). Bolton, MA: Anker.

Duffy, D. K., \& Jones, J. W. (1995). Teaching within the rhythms of the semester. San Francisco, CA: Jossey-Bass.

Feder, J. (1988). Fractals. New York, NY: Plenum Press.

Feldman, K. A. (1986). The perceived instructional effectiveness of college teachers as related to their personality and attitudinal characteristics: A review and synthesis. Research in Higher Education, 24(2), 139-213.

Fish, S. (2005, February 4). Who's in charge here? Retrieved May 30, 2006, from The Chronicle of Higher Education web site: http://chronicle.com/jobs/2005/ 02/2005020401c.htm

Gleick, J. (1987). Chaos: Making a new science. New York, NY: Penguin Books.

Hamermesh, D. S., \& Parker, A. M. (2005, August). Beauty in the classroom: Instructors' pulchritude and putative pedagogical productivity. Economics of Education Review, 24(4), 369-376.

Iannaccone, P. M., \& Khokha, M. (Eds.). (1996). Fractal geometry in biological systems: An analytical approach. Boca Raton, FL: CRC Press.

Jacobs, L. C., \& Chase, C. I. (1992). Developing and using tests effectively: A guide for faculty. San Francisco, CA: Jossey-Bass.

Leamnson, R. (1999). Thinking about teaching and learning: Developing habits of learning with first year college and university students. Sterling, VA: Stylus.

Liebovitch, L. S. (1998). Fractals and chaos simplified for the life sciences. New York, NY: Oxford University Press.

Loacker, G. (Ed.). (2000). Self assessment at Alverno College. Milwaukee, WI: Alverno College.

Maki, P. L. (2004). Assessing for learning: Building a sustainable commitment across the institution. Sterling, VA: Stylus.

Mandelbrot, B. B. (1982). The fractal gcometry of nature. New York, NY: W. H. Freeman.

Nuhfer, E. B. (2003a). Content coverage, courses, and controversy part 1: Developing in fractal patterns V. National Teaching and Learning Forum, 13(1), 8-10.

Nuhfer, E. B. (2003b). Developing in fractal patterns I: Moving beyond diagnoses, evaluations, and fixes. National Teaching and Learning Forum, 12(2), 7-9. 
Nuhfer, E. B. (2003c). Developing in fractal patterns II: A tour of the generator. $\mathrm{Na}$ tional Teaching and Learning Forum, 12(4), 9-11.

Nuhfer, E. B. (2004a). Fractal thoughts on the forbidden affective in teaching evaluation and high level thinking: Educating in fractal patterns X. National Teaching and Learning Forum, 14(1), 9-11.

Nuhfer, E. B. (2004b). Why rubrics? Educating in fractal patterns IX. National Teaching and Learning Forum, 13(6), 9-11.

Nuhfer, E. B. (2005a). DeBono's red hat on Krathwohl's head: Irrational means to rational ends-more fractal thoughts on the forbidden affective: Educating in fractal patterns XIII. National Teaching and Learning Forum, 14(5), 7-11.

Nuhfer, E. B. (2005b). A fractal thinker looks at student evaluations. Retrieved May 30, 2006, from the Idaho State University, Center for Teaching and Learning web site: www.isu.edu/ctl/facultydev/extras/MeaningEvalsfract_files/MeaningEvalsfract.htm

Nuhfer, E. B. (2005c). Fractal views on good testing practices: Educating in fractal patterns XII. National Teaching and Learning Forum, 14(4), 9-11.

Nuhfer, E. B. (2005d). Perceiving education's temporal temperaments (part A-patterns): Educating in fractal patterns XIV. National Teaching and Learning Forum, 14(6), 7-10.

Nuhfer, E. B. (2005e). Perceiving education's temporal temperaments (part B-age, order, duration, frequency, rate, and magnitude): Educating in fractal patterns XIV. National Teaching and Learning Forum, 15(1), 8-11.

Nuhfer, E. B. (2005f). Tests as anchors that wobble: Understanding imperfect correlations in educational measurements: Educating in fractal patterns XI. National Teaching and Learning Forum, 14(2), 8-11.

Nuhfer, E. B., \& Adkison, S. (2003). Unit level development: Teaching philosophies at the unit level: Educating in fractal patterns IV. National Teaching and Learning Forum, 12(6), 4-7.

Nuhfer, E. B., Chambers, F., \& Heckler. (2002, June). Teaching in fractal patterns: Recursive connections of assessment, individual faculty development, and unit level development. Paper presented at the Pacific Planning, Assessment, and Institutional Research Conference, Honolulu, $\mathrm{HI}$.

Nuhfer, E. B., \& Knipp, D. (2003). The knowledge survey: a tool for all reasons. In C. M. Wehlburg \& S. Chadwick-Blossey (Eds.), To improve the academy: Vol. 21. Resources for faculty, instructional, and organizational development (pp. 59-78). Bolton, MA: Anker. Addenda available electronically. Retrieved May 30, 2006, from the Idaho State University, Center for Teaching and Learning web site: - www.isu.edu/ctl/facultydev/ADDENDUM.htm 
Nuhfer, E. B., Krest, M., \& Handelsman, M. (2003). A guide for composing teaching philosophies: Developing in fractal patterns III. National Teaching and Learning Forum, 12(5), 10-11.

Nuhfer, E. B., Leonard, L., \& Akersten, S. (2004). Content coverage, courses, and controversy part 2: Developing in fractal patterns VI. National Teaching and Learning Forum, 13(2), 8-11.

Nuhfer, E. B., \& Pavelich, M. (2001). Levels of thinking and educational outcomes. National Teaching and Learning Forum, 11(1), 5-8.

Nuhfer, E. B., \& Pavelich, M. (2002). Using what we know to promote high level thinking outcomes. National Teaching and Learning Forum, 11(3), 6-8.

Nuhfer, E. B., \& Pletsch, C. (2002, June). Educating in fractal patterns: Linking development, instruction, and assessment from the individual to unit levels. Pre-conference workshop presented at the American Association for Higher Education assessment conference, Boston, MA.

Nuhfer, E. B., \& Pletsch, C. (2003, June). Harnessing the power of fractal thinking in education, assessment, and faculty development. Pre-conference workshop presented at the American Association for Higher Education assessment conference, Seattle, WA.

Smith, D. M., \& Kolb, D. A. (1986). The user's guide for the learning-style inventory: A manual for teachers and trainers. Boston, MA: McBer.

Theall, M., Abrami, P. C., \& Mets, L. M. (Eds.). (2001). New directions for institutional research: No. 109. The student ratings debate: Are they valid? How can we best use them? San Francisco, CA: Jossey-Bass.

Trout, P. A. (1997, September/October). What the numbers mean: Providing a context for numerical student evaluations of courses. Change, 29(5), 24-30.

Wheatley M. J. (1992). Leadership and the new science: Learning about organization from an orderly universe. San Francisco, CA: Berrett-Koehler.

Wirth, K. R., Perkins, D., \& Nuhfer, E. B. (2005). Knowledge surveys: A tool for assessing learning, courses, and programs [Abstract]. Geological Socicty of America Annual Meetings Program with Abstracts, 37(7), 119.

Wright, B. (2001). Accreditation where credit is due. In L. Suskie (Ed.), Assessment to promote decp learning: Insight from AAHE's 2000 and 1999 assessment conferences (pjp. 49-58). Sterling, VA: Stylus.

Zull, J.E. (2002). The art of changing the brain: Enriching the practice of teaching by exploring the biology of learning. Sterling, VA: Stylus. 